\title{
Pattern of Ocular Morbidity in Professional Intercity Vehicle Drivers of Mid West Tarai Belt of Nepal: A Cross Sectional Descriptive Study
}

\author{
Bastola P
}

\begin{abstract}
Background: Visual function is very important in driving. The diseases of the ocular organs and its adnexa can adversely affect the visual functions of the driver, resulting into serious implications in road safety. Aim: Finding out the profile and pattern of ocular morbidity in professional intercity vehicle drivers of Mid West Tarai region of Nepal. Methodology: This was a cross sectional, descriptive, community/hospital based study carried out in two of the busiest bus parks of Mid West Tarai region of Nepal. All professional drivers with a valid government driving license who had been driving as professional drivers for more than 3 months were enrolled. Results: Of the 256 participants in the study, all of the professional drivers were males. In 162 (66.4\%) of the study participants did not have ocular examination before issuing or during renewal of the driving license. More than $50 \%$ of ocular morbidity was due to dry eyes, ocular allergy, uncorrected refractive error and conjunctival degenerative conditions in all age groups. Presbyopia and cataract in subjects above 40 years accounted for 34 (13\%) and 10(3.9\%) respectively. 16(6.2\%) of study participants were still driving with valid license despite having total color blindness. Conclusion: Every potential driver at first licensing and at renewals should be subjected to basic vision tests. Color vision test should be made prerequisite for all the drivers before issuing a government license. Those found to have visual impairment should be referred to ophthalmologists for detailed ocular evaluation and periodic ocular examination.
\end{abstract}

Key words: Color blindness, dry eyes, presbyopia, professional drivers, road traffic accident

\section{INTRODUCTION:}

Driving is defined as the ability to operate, control, and direct the course of a vehicle. ${ }^{1}$ Road Traffic Accidents (RTA) remains a dreadful plague all over the world; in developed world it is in declining trend however the reverse applies for developing countries, and a perfect vision for professional drivers is a must for driving and safety of other road users ${ }^{2}$.

In Nepal, 1,545,988 vehicles have been registered till the year 2013 as per data from Department of Traffic Management and Traffic Directorate Nepal police 2013., Total number of road fatalities in past decade in Nepal is in decreasing trend in the year 2002, 2003, 2004 and 2005 when compared with base year 2001 but increased since 2006. It seems very much threatening in $2009^{4}$. The data of the year 2012-2013 show that 13,582 RTAs occurred in Nepal resulting into case fatality ratio of 11.75 per 1000 vehicles ${ }^{4}$.

Worldwide, it has been estimated that the number of people killed in RTAs each year is about 1.2 million, while the number

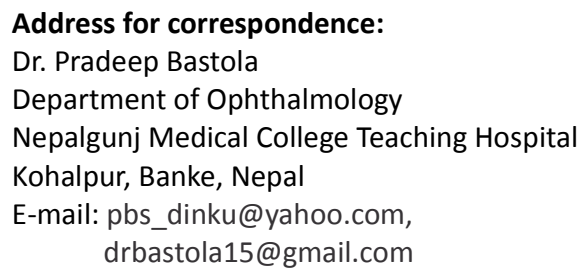

of the injured could be as high as 50 million $^{5}$. It is more disturbing to note that young adult group or people in their active working age group; the socio economic back bone of the country are affected most by this ravaging menace ${ }^{6}$.

Driving requires several sets of abilities including sensory (mainly visual), mental ability, motor ability and compensatory abilities. Total of $95 \%$ of sensory ability needed for driving has been shown to be visual ${ }^{7}$, however; various published results of different researchers have shown no significant correlation between RTAs and visual disfunction ${ }^{7-14}$.

The present study aimed to find out the types and prevalence of ocular and adnexal diseases among commercial intercity professional vehicle drivers in Mid West Region of Nepal. To the best of the author's knowledge, no such reports are published before in Mid West Region of Nepal.

\section{METHODOLOGY}

This was a hospital/community based, descriptive, cross sectional study carried out in two of the busiest bus parks of Mid West Nepal. After ocular examination of the professionals drivers at Kohalpur Bus Park and Nepalgunj Bus Park, referral was done to Nepalgunj Medical College and Teaching Hospital (NGMCTH), department of Ophthalmology, Banke, Nepal for detail examination. The study period was from May 2014 to June 2014. 
Bastola P: Pattern of Ocular Morbidity in Professional Intercity Vehicle Drivers of Mid West Tarai Belt of Nepal: A Cross Sectional Descriptive Study

Drivers driving vehicles for at least last 3 months or more with a government issued valid driving license were included in the study. Participants not willing to be part of study, not having a valid government issued license, private vehicle drivers, not having a prior experience of 3 months of continuous professional driving were excluded from the study.

The study strictly adhered to the declaration of tenets of Helsinki ${ }^{15}$. An ethical informed consent was taken from Nepalgunj Medical College and Teaching Hospital (NGMCTH), Kohalpur, Nepalgunj.

All the participants were examined by a single examiner. A detailed ocular examination including color vision test and posterior segment examination was carried out at hospital examination centres.

Following were the definitions used in the study. Education level was categorized in to literate (being able to read) and illiterate (not able to read at all). Uncorrected refractive error was defined as a visual acuity of 6/12 or less in the better eye unaided; improving with pin hole. Age related presbyopia in participants of 40 years and above were included as a separate entity in the study, when other co morbidity was not diagnosed. Socioeconomic status was assessed to know the compliance of medical advice for participants. Socioeconomic status was then categorized in to 1) below poverty line 2) poor 3) low income 4) middle income and 5) high income. A participant's income less than 100 Nepali Rupees (One dollar) per day was categorized as below poverty line in this study.

Participants needing treatment medical or surgical were referred to NGMCTH. Medical treatment was provided free of cost, while surgical treatment was subsidized to nominal price. The data obtained from the study was entered in Microsoft Excel version 2013, STATA version 13 and statistical analysis was done. A statistician was consulted when and where necessary.

\section{RESULTS}

A total of 512 eyes of 256 participants were examined. Gender wise all the participants were males. Age wise; participants in the active working age group were the most; accounting for more than 162(63\%) of all participants (Age group $20-39$ ), while participants of 40 years and above accounted for $76(30 \%)$ (Table I). Of the 256 participants; 244 (95.3\%) were literate, while 12(4.6) participants were illiterate (Figure 1).

None of the participants fell in the category below poverty line or above income group. Out of 256 participants 178 (69.5\%) were in middle income group category and 78 (30.4\%) belonged to the low income group category showing good compliance of doctors advice. Eye examination showed, dry eyes (16\%), presbyopia (13.2\%), uncorrected refractive error (9.3\%) and ocular allergy $(9.8 \%)$ as the commoner ocular morbidities.

\begin{tabular}{|c|c|c|}
\hline $\begin{array}{c}\text { Age Range } \\
\text { (In years) }\end{array}$ & $\begin{array}{c}\text { Number of } \\
\text { Participants }\end{array}$ & Percentage (\%) \\
\hline $10-19$ & 18 & 7.0 \\
\hline $20-29(\#)$ & 54 & 21.0 \\
\hline $30-39(\S \S)$ & 108 & 42.1 \\
\hline $40-49$ & 39 & 15.2 \\
\hline $50-59$ & 25 & 9.7 \\
\hline $60-69$ & 12 & 4.6 \\
\hline Total & 256 & 100 \\
\hline
\end{tabular}

\#, $\S \S=$ Showing $63.1 \%$ of the study participants in active working age group.

Table I: Showing the age range of study participants in the study



Figure 1: Showing the literacy level of the study participants

Pterygium and other conjunctival degenerations accounted for over $11 \%$ of the study participants. Color blindness and cataracts accounted for $6.2 \%$ and $3.9 \%$ of study participants (Table II).

In the study group, only 80 participants (33.5\%) clearly answered that they had an ocular examination done prior to getting driving license and others had some health checkup.

\section{DISCUSSION}

Of all the 256 participants were males as professional driving is done by males only in the region. The participants belonged to active working age group were $162(63 \%)$ while, $76(29.5 \%)$ of the participants were above the age of 40 years. Interestingly, $18(7 \%)$ were very young and teenagers. 
Bastola P: Pattern of Ocular Morbidity in Professional Intercity Vehicle Drivers of Mid West Tarai Belt of Nepal: A Cross Sectional Descriptive Study

\begin{tabular}{|c|c|c|}
\hline Type of Ocular Morbidity & Number ( $n=512$ Eyes) & Percentage (\%) \\
\hline DryEye & $41(82)$ & 16.0 \\
\hline Ocular Allergy & $25(50)$ & 9.8 \\
\hline Uncorrected Refractive Error & $24(48)$ & 9.3 \\
\hline Presbyopia & $34(68)^{*}$ & 13.2 \\
\hline Cataract (of any type and grade) & $10(20)$ & 3.9 \\
\hline Mebomian Gland Dysfunction & $14(28)$ & 5.4 \\
\hline Pinguencula & $13(26)$ & 5.0 \\
\hline Corneal Opacity & $7(14)$ & 2.7 \\
\hline Squamous Blepharitis & $6(12)$ & 2.3 \\
\hline Pterygium & $12(24)$ & 4.7 \\
\hline Chalazion & $3(6)$ & 1.1 \\
\hline Conjunctival Nevus & $3(6)$ & 1.1 \\
\hline Colour Blindness & $16(32)^{* *}$ & 6.2 \\
\hline Iris Nevus & $2(4)$ & 0.7 \\
\hline Chronic Uveitis & $2(4)$ & 0.7 \\
\hline Hypertensive Retinopathy & $2(4)$ & 0.7 \\
\hline Diabetic Retinopathy & $3(6)$ & 1.1 \\
\hline Acquired/Congenital Ptosis & $3(6)$ & 1.1 \\
\hline Asthenopia & $3(6)$ & 1.1 \\
\hline Pseudophakia & $2(4)$ & 0.7 \\
\hline Solar Maculopathy & $2(4)$ & 0.7 \\
\hline Computer Vision Syndrome & $3(6)$ & 1.1 \\
\hline Strabismus & $2(4)$ & 0.7 \\
\hline Chronic Dacryocystitis & $3(6)$ & 1.1 \\
\hline Dysthyroid Ophthalmopathy & $2(4)$ & 0.7 \\
\hline Glaucoma (all types) & $3(6)$ & 1.1 \\
\hline Other Conjunctival Degeneration & $3(6)$ & 1.1 \\
\hline Optic Neuropathy & $2(4)$ & 0.7 \\
\hline No Abnormality Detected & $11(22)$ & 4.2 \\
\hline Total & 256 ( $n=512$ Eyes) & 100 \\
\hline
\end{tabular}

$*=$ Higher percentage of uncorrected presbyopia in study participants

$* *=16$ participants having total color blindness

Table II: showing the pattern of ocular morbidity amongst study participants 
In a study done in Nigeria ${ }^{16}$, more than $2 / 3$ professional drivers were more than 40 years and more than $1 / 5^{\text {th }}$ were above 50 years age wise, which differed from the finding of this study.

In this study; $95.3 \%$ of the study participants had formal basic education, knowing "Traffic Rules" while mere $4.7 \%$ drivers were illiterate. However; there is still a pressing need to increase the literacy level of the drivers to reduce road traffic accidents (RTAs).

In $170(66.4 \%)$ study participants answered that they did not have an ocular examination test including color vision before they were issued driving license; 86 (33.6\%) answered they had their eyes examined before the license was issued. This finding again justifies the fact that routine eye examinations, as required, are not taken seriously before issuing valid driving license. This finding is in agreement with number of studies done in other countries. ${ }^{17-19}$

Dry eyes, ocular allergy, uncorrected refractive error as expected were common accounting for $16.0 \%, 9.8 \%$ and $9.3 \%$ of the study participants. Dry eyes and ocular allergy were found overlapping in few study participants.

Participants of 40 years or above having presbyopia accounted for $34(13.2 \%)$. The high percentage of presbyopia in this age group could be age related and subjects were unaware about ageing eye changes. These findings are similar ${ }^{19}$ and higher as reported in other study ${ }^{20}$. In 10(3.9\%) participants age related cataract in both eyes which was diagnosed and referred for surgery immediately. The finding again correlated with the study participants age, $76(30 \%)$ above 40 years of age and above had age related changes.

Surprisingly, the finding which came out from the study was 16(6.2\%) participants of total 256 had bilateral total color blindness. The study participants were unaware about it.

There were $42(16 \%)$ participants who had some kind of ocular surface disorder and conjunctival degenerations like mebomian gland dysfunction, pterygium, pinguencula and other conjunctival degenerations. This may be attributed to poor working conditions. Exposure to ultraviolet light, is more, especially in Mid West Terrain region, high temperature during summer season and lack of protective sun glasses.

\section{Limitations of the study}

This study sample does not represent all the professional intercity drivers of Nepal; which is a major limitation of the study. Due to lack of more appropriate data a correlation between RTA and ocular morbidity could not be done. A larger scale study with a bigger sample size and more data from government of Nepal would certainly help to conclude newer findings. However; this study will work as a baseline for further studies of similar kind in other parts of Nepal.

\section{CONCLUSION/RECOMMENDATIONS}

People of active work age group were involved in professional driving in the study area; however people of 40 years and above were also continuing the profession.

The common ocular morbidities amongst intercity professional drivers in Mid-West region of Nepal were dry eyes, ocular allergy, uncorrected refractive error and conjunctival degenerations. Presbyopia was still a major problem in drivers of 40 years and above.

Cataract was the potentially blinding ocular disease seen. Glaucoma cases were only 3 (1.1\%). This highlights the need for renewed efforts to educate vulnerable groups on these preventable causes of blindness and visual impairment, by ensuring that every potential driver at first licensing and at renewals gets the basic vision test done. Color vision test should be made must for all the drivers. Those found to have visual impairment should be referred to ophthalmologists for detailed ocular evaluation.

\section{ACKNOWLEDGMENTS}

I would like to sincerely thank all the study participants for being part of the study. I would like to also acknowledge Nepalgunj Medical College and Teaching Hospital for managing the camps, providing technical support including examination of the participants and further treatment.

I would like to acknowledge my team members Dr. Gunjan Pokhrel, Mr. Neeraj Dhungana and Mr. Yam Bahadur Khadka NGMCTH.

Finally, I would like to acknowledge the Lions clubs of Nepalgunj and Kohalpur region (325B2) for arrangement of such a wonderful camp and for collaboration with NGMCTH.

\section{REFERENCES}

1. Driving. Oxford Advanced Learner's Dictionary. Fifth edition. Oxford: A S Hornsby, 1995:356.

2. Willette RE, Walsh JM. Drugs, driving and traffic safety. WHO Offset publication No.78. World Health Organization. Geneva; 1983. p.1-10.

3. Thapa AJ. Progress Report of Department of Transport Management in: Status paper on road safety in Nepal 2013. (cited January 2015 ). Available on I ine: http://www.dor.gov.np/documents/Status_Paper\%20_2013.pd f. 26 page report.

4. Thapa AJ. Traffic Accident Records, Traffic Directorate, Nepal Police. in: Status paper on road safety in Nepal 2013 (cited January 2015 ). Available online: 
http://www.dor.gov.np/documents/Status_Paper\%20_2013.pd f2015. 26 page report

5. Odero W, Garner P, Zwi A. Road traffic injuries in developing countries: a comprehensive review of epidemiological studies. Tropical Medicine and International Health 1997;2:445-460.

6. Oyemade A. Epidemiology of road traffic accidents in Ibadan and its environs. Niger Med J. 1973, 3:174-7.

7. Taylor JF. Vision and driving. Practitioner 1982;226:885-9.

8. Cashell GT. Visual functions in relation to road accident. Trans Ophthalmol Soc. 1966;86:617-20.

9. Nwosu SN. Visual impairment and road traffic accident in Nigeria professional drivers. Orient J Med.1991;3:110-2.

10. Okafor CR. Visual status of Nigerian police force drivers. (Masters Dissertation) Lagos, Nigeria: National Postgraduate Medical College of Nigeria. Lagos, Nigeria. ;1992.

11. Effiong B. Visual Status of Taxi Park Drivers in Enugu. in: Dissertation Submitted to National Postgraduate Medical College of Nigeria. Lagos, Nigeria. ; November 1993.

12. Burg A. The Relationship between vision test scores and driving record: Geneva Finding, Dept of Engineering, Los Angeles, University of California. 1968;68:27-46. Report

13. Council FM, Allen IA. A Study of the visual fields of North Carolina drivers and their relationship to accidents. University of North Carolina, North Carolina High Way and Safety Research Center. 1974:18-26.Report.

14. Griep DJ. Traffic, accidents, visual performance and driving behaviour. In: Henkes HE, editor. Perspective in Ophthalmology. Amsterdam: Xcerpta Medica Foundation; 1968:231-8.

15. WMA Declaration of Helsinki - Ethical Principles for Medical Research Involving Human Subjects. (cited January, 2015).
A v a i I a b I e
o n I i n e :

http://www.wma.net/en/30publications/10policies/b3/.

16. Davison PA. Interrelationship between British drivers visual abilities, age and road accidents histories.Ophthal Physiol Opt 1985;5:195-204.

17. Nwosu SN. Visual impairment and road traffic accident in Nigeria professional drivers. Orient J Med 1991;3:110-2.

18. Oladehinde MK, Adeoye AO, Adegbehingbe BO, Onakoya AO. Visual functions of commercial drivers in relation to road accidents in Nigeria. Indian J Occup Environ Med 2007;11:71-5.

19. Bola JA, Joshua FO, Feyi GA. Pattern of Eye Diseases among Commercial Intercity Vehicle Drivers in Nigeria. Nigerian J of Ophthalmol 2008;16(2):55-59.

20. Falola A. A survey of the visual status of Nigerian army drivers in Lagos area. (Masters Dissertation cited January, 2015) Lagos, Nigeria: National Postgraduate Medical College of Nigeria. Lagos, Nigeria; May 2000. 